DIVISION OF THE HUMANITIES AND SOCIAL SCIENCES

CALIFORNIA INSTITUTE OF TECHNOLOGY

PASADENA, CALIFORNIA 91125

A DYNAMIC MIGRATION MODEL WITH UNCERTAINTY

Mahmoud A. El-Gamal

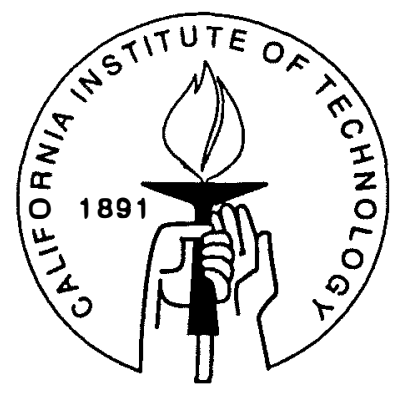

SOCIAL SCIENCE WORKING PAPER 843

March 1993 


\title{
A Dynamic Migration Model with Uncertainty
}

\author{
Mahmoud A. El-Gamal
}

\begin{abstract}
We study a dynamic version of the Harris-Todaro migration model where a finite population of infinitely lived Bayesian agents choose consumption and migration decision rules as a function of their histories. The agents do not know the production functions in the two sectors and learn about them through wage draws that they receive from the stochastic production functions. The government knows the true production functions but is uninformed about the agents' beliefs, and the actual wage draws they observe. The government maximizes its welfare function using wage subsidies in the two sectors, and a migration tax. We solve the agents' dynamic programming problem, and then use the solution to solve the government's dynamic programming problem. We study the effects of government policies on the population distribution, and illustrate the model by numerically solving a particular parametric example.
\end{abstract}

Keywords: Harris-Todaro Model, Migration, Bayesian learning, Sequential Statistical Decision Framework

Forthcoming: Journal of Economic Dynamics and Control 


\title{
A Dynamic Migration Model with Uncertainty
}

\author{
Mahmoud A. El-Gamal *
}

\section{Introduction}

The Harris-Todaro model (1970) of labor migration may still be the most influential model in the development literature. A number of extensions and variations have been offered within its static context (e.g. Bhagwati and Srinivasan (1974), Stiglitz (1974), Corden and Findlay (1975), Calvo (1978), Khan (1980), Lundborg (1990), McCool (1982), to name but a few). Migration models with uncertainty and/or of dynamic nature have mostly been on the micro (individual) level (e.g. Djiajic (1989), Pessino (1991), and Pollachek and Horvath (1978)), or concentrated on steady state equilibria (e.g. Galor (1986)). On the macro level, however, the spirit of modeling and policy prescriptions in the literature remains mainly tied to the Harris-Todaro static setting with deterministic production functions, and full information on the agents' and the government's side.

This paper has the modest purpose of developing a general (and yet computable) model in the spirit of the original Harris-Todaro model, with two main differences. The first difference is adding a stochastic component to production together with adding uncertainty on the agents' as well as the government's side. The second variation we include is a fully dynamic setting with a finite population that uses optimal (Bayesian) updating procedures to learn the true production functions in the rural and urban sectors, while at the same time maximizing the discounted sum of a stream of lifetime utilities from consumption. The government takes the solutions of the agents' dynamic programming problem as a primitive, and proceeds to maximize its own discounted stream of social welfare as it learns about the distribution of beliefs in the population through the observed migration patterns.

The target of the paper agrees with the bulk of the above referenced static models in analyzing government policies of distributing wage subsidies and imposing migration taxes (possibly prohibitively high) to obtain a first best distribution of population

- This paper was presented at the SEDC summer meetings in Montreal, June 1992. I wish to thank the participants in the conference, especially Thomas Sargent, for their helpful comments. I also wish to thank two anonymous referees and the editor of JEDC (Berç Rustem) for insisting on explicit policy analysis, which has significantly improved the paper. Finally, I wish to thank the Jet Propulsion Laboratory for giving me access to their Cray YMP2E/116. 
between the two sectors. Within our dynamic setting, we introduce a social welfare function which the government wishes to maximize using the wage subsidy and migration tax policy tools. We show that, under simplifying assumptions, an equilibrium to the government/population game exists. The agent's dynamic program gives rise to an optimal migration rule which the government can then use to formulate beliefs about migration patterns in the future. The government uses the latter beliefs to construct its own well defined dynamic program which allows for an optimal rule of setting wage subsidies and migration taxes as a function of the current population distribution and government beliefs about the distribution of agent beliefs. The setting of the model is general enough to allow for a large class of production functions, agent utility functions, and government welfare functions.

In section 2, we introduce the model at the individual level and demonstrate that the individual's dynamic programming problem is well defined and gives rise to a well defined optimal migration rule. In section 3 , we study that optimal migration rule and derive the micro-dynamics summarized by each agent's transition probability matrix between the sectors as a function of that agent's belief, the population distribution, and the announced subsidy and migration tax levels. In section 4 we derive the resulting aggregate dynamics in the form of the government's probability transition matrix for the population as a function of the government's beliefs on agent beliefs. In section 4 , we also derive the government's updating rule for its beliefs on generic agent beliefs as the population distribution changes due to migration. In section 5 , we demonstrate that the government's dynamic welfare maximization problem is itself well defined, and hence that the optimal tax and subsidy policy is well defined. In section 6, we establish, under further simplifying conditions, the effects of the various government policies on population dynamics, as well as the need for government intervention. In section 7, we provide a simple numerical example to demonstrate how the optimal subsidy and tax function can be found. The parameterization of our numerical example was chosen in the spirit of the Harris-Todaro model and is used to illustrate the effect of the dynamic and uncertainty features of our model.

\section{Description of the model}

The economy has $N$ infinitely lived agents and two sectors (labelled $r$ and $u$ for rural and urban, resp.). In the beginning of each period, agents decide on their level of consumption for the period (subject to some budget constraints) and the sector in which they will work during this period. They consume the chosen amount, then they migrate if necessary. After that, they work in the designated sector, and then receive their wages in that sector. At the time the agents receive their wages, they are also informed of the population distribution for this period. The government, on the other hand, observes the migration of the workers, and collects a pre-specified migration tax. After the workers have settled in the sector of their choice for that time period and started working, the government observes the population distribution and decides on next period's migration tax as well as the current period's wage subsidies for the two sectors, which are distributed at the 
time the workers receive their wages. The time structure of the model is described by Figure 1.

\begin{tabular}{l|l|l|l|l|l}
\hline $\begin{array}{l}\text { Government: } \\
\text { Announces } \\
\text { population } \\
\text { Distribution and } \\
\text { pays subsidies }\end{array}$ \\
\hline $\begin{array}{l}\text { Agent: } \\
\text { Learns pop. } \\
\text { distribution and } \\
\text { receives wages } \\
\text { and subsidies }\end{array}$
\end{tabular}

Figure 1: Time line for the agents and the government

At this point, it would help to introduce some notation. For each agent, let $w_{t}^{i}$ denote the wage received in sector $i$ in period $t$, let $c_{t}$ denote the level of consumption chosen in period $t$, and let $l_{t}$ denote the location (sector) in which that agent decides to work in period $t$. We shall use $l_{t} \in\{r, u\}$ for superscripts, and give it the numerical values $r \equiv 1$, $u \equiv 0$ in equations. We use $N_{t}^{r}$ to denote the population in the rural sector in period $t$, and $N_{t}^{u}=N-N_{t}^{r}$ to denote the population in the urban sector during that period. We shall denote the wage subsidies in the rural and urban sectors in period $t$ by $s_{t}^{r}$ and $s_{t}^{u}$, respectively. The migration tax for period $t$ is denoted by $\tau_{t}$.

The wages are assumed to be determined stochastically via production functions that depend on the population distribution $N^{r}$ and $N^{u}$ and some unknown parameters $\theta^{r}$ and $\theta^{u}$. In reduced form we write the wage distributions as follows:

$$
\begin{aligned}
w_{t}^{r} & \sim F^{r}\left(d w ; \theta^{r}, N_{t}^{r}\right) \\
w_{t}^{u} & \sim F^{u}\left(d w ; \theta^{u}, N_{t}^{u}\right)
\end{aligned}
$$

where the dependence on $N_{t}^{r}$ and $N_{t}^{u}$ should account for any returns to scale considerations, and $\theta=\left(\theta^{r}, \theta^{u}\right)$ is some technological parameter unknown to the agents but known to the government. The support of $F^{r}(. ; .,$.$) and F^{u}(. ; .,$.$) is assumed to be the$ set $W=[0, \bar{w}]$. In what follows, we shall assume that $F^{r}$ and $F^{u}$ have densities $f^{r}$ and $f^{u}$ respectively. The government chooses subsidies $s_{t}^{r}, s_{t}^{u}$ from the set $S=[0, \bar{s}]$, and 
migration $\operatorname{tax} \tau_{t}$ from the set $[0, \bar{\tau}]$. We assume that $\bar{s}$ and $\bar{\tau}$ are preset to satisfy some social and/or legal restrictions.

When making their decisions, the agents are assumed to be boundedly rational in two senses. First, they assume that the population distribution will stay the same in the next period and that their decision to migrate or not to migrate cannot influence that. Secondly, they assume that the subsidy levels in both sectors, and the migration tax, will be the same in the next period as they have been in the current period. We shall discuss the technical and substantive reasons for making those assumptions in the remarks following the mathematical definition of the dynamic programming problem. The agent's problem is thus:

$$
\begin{gathered}
\max _{\left\{l_{t}, c_{t}\right\}} E_{0} \sum_{t=0}^{\infty} \beta^{t} u\left(c_{t}\right) \\
\text { s.t. } \quad 0 \leq c_{t} \leq w_{t-1}^{l_{t}-1}+s_{t-1}^{l_{t-1}}-\tau_{t}\left|l_{t}-l_{t-1}\right| \\
l_{t} \in\{r, u\} \equiv\{1,0\} \\
w_{t}^{r} \sim F^{r}\left(d w ; \theta^{r}, N_{t-1}^{r}\right) \\
w_{t}^{u} \sim F^{u}\left(d w ; \theta^{u}, N_{t-1}^{u}\right) \\
s_{t}^{r}=s_{t-1}^{r} \\
s_{t}^{u}=s_{t-1}^{u} \\
\tau_{t+1}=\tau_{t} \\
\lambda_{t+1}^{r}(A)=\frac{\int_{A} l_{t} \lambda_{t}^{r}(d \theta) f^{r}\left(w_{t}^{r} ; \theta, N_{t}^{r}\right)}{\int_{\Theta^{r}} \lambda_{t}^{r}(d \theta) f^{r}\left(w_{t}^{r} ; \theta, N_{t}^{r}\right)}+\left(1-l_{t}\right) \lambda_{t}^{r}(A) \\
\int_{t+1}^{u}(B)=\frac{\int_{\Theta^{u}} \lambda_{t}^{u}(d \theta) f^{u}\left(w_{t}^{u} ; \theta, N_{t}^{u}\right)}{\left.l_{t}\right) \lambda_{t}^{u}(d \theta) f^{u}\left(w_{t}^{u} ; \theta, N_{t}^{u}\right)}
\end{gathered}
$$

where $A$ is a Borel subset of $\Theta^{r}, B$ is a Borel subset of $\Theta^{u}$, and $\lambda_{t}^{r}$ and $\lambda_{t}^{u}$ are the agent's beliefs in period $t$ about $\theta^{r}$ and $\theta^{u}$, respectively. The problem, thus, reduces to the simple dynamic program (where $\mathfrak{B}$ stands for Bayesian updating):

$$
\begin{gathered}
\max _{\left\{l_{t} \in\{r, u\}\right\}} \sum_{t=0}^{\infty} \beta^{t}\left[\int_{\theta^{r}} \int_{\Theta^{u}} \int_{W} \int_{W} u\left(l_{t}\left(w_{t}^{r}+s_{t}^{r}\right)+\left(1-l_{t}\right)\left(w_{t}^{u}+s_{t}^{u}\right)-\tau_{t}\left|l_{t}-l_{t-1}\right|\right)\right. \\
\left.F^{r}\left(d w_{t}^{r} ; \theta^{r}, N_{t-1}^{r}\right) F^{u}\left(d w_{t}^{u} ; \theta^{u}, N_{t-1}^{u}\right) \lambda_{t}^{r}\left(d \theta^{r}\right) \lambda_{t}^{u}\left(d \theta^{u}\right)\right]
\end{gathered}
$$

s.t.

$$
\begin{gathered}
s_{t}^{r}=s_{t-1}^{r} \\
s_{t}^{u}=s_{t-1}^{u} \\
\tau_{t+1}=\tau_{t}
\end{gathered}
$$




$$
\begin{aligned}
\lambda_{t+1}^{r}(A) & =\frac{\int_{A} l_{t} \lambda_{t}^{r}(d \theta) f^{r}\left(w_{t}^{r} ; \theta, N_{t}^{r}\right)}{\int_{\Theta^{r}} \lambda_{t}^{r}(d \theta) f^{r}\left(w_{t}^{r} ; \theta, N_{t}^{r}\right)}+\left(1-l_{t}\right) \lambda_{t}^{r}(A)=\mathfrak{B}\left(\lambda_{t}^{r}, N_{t}^{r}, w_{t}^{r}, l_{t}\right)(A) \\
\lambda_{t+1}^{u}(B) & =\frac{\int_{B}\left(1-l_{t}\right) \lambda_{t}^{u}(d \theta) f^{u}\left(w_{t}^{u} ; \theta, N_{t}^{u}\right)}{\int_{\Theta^{u}} \lambda_{t}^{u}(d \theta) f^{u}\left(w_{t}^{u} ; \theta, N_{t}^{u}\right)}+l_{t} \lambda_{t}^{u}(B)=\mathfrak{B}\left(\lambda_{t}^{u}, N_{t}^{u}, w_{t}^{u}, l_{t}\right)(B)
\end{aligned}
$$

\section{Remarks}

- Notice that different workers in the same sector are allowed to get different random draws from the wage distribution. This is more general than the Harris-Todaro model. The analysis below will be slightly easier if we force all workers within a sector to receive the same wage. Notice, moreover, that unemployment is a special case of this specification where the distribution of wages has an atom at zero wage, in which case the subsidies also serve as unemployment benefits.

- To form rational beliefs about $N_{t}^{r}, N_{t}^{u}, s_{t}^{r}$, and $s_{t}^{u}$ would involve solving the government's problem as well, which is too much to require from our agents. We believe that the bounded rationality assumption that their migration decision (and their new observations) do not affect the population distribution is quite reasonable. Indeed, this assumption is in the same spirit of the Harris-Todaro assumption that agents know their expected wage in the other sector when they decide to migrate. This implies either their knowledge of the population distribution in the next period, or their assumption that the population distribution will remain unchanged. Since the former implication leads to more technical complications (see next remark), we resort to the latter.

- On a more technical note, if we let agents form beliefs about the beliefs of the other agents in order to form a distribution of possible migration patterns, their own decision to migrate will now depend on their beliefs about the other agents' beliefs. It is clear that this will lead to infinite regress (beliefs on beliefs on ...) whose dynamics can be very complicated (e.g. see El-Gamal (1992)). In this paper, those problems are bypassed by this bounded rationality assumption.

- More complications can be added to the model. For example, the wage distribution could be made to depend on the person's tenure/experience in the sector $\epsilon_{t}^{r}=$ $\sum_{\rho=0}^{t} l_{\rho}$ and $\epsilon_{t}^{u}=t-\epsilon_{t}^{r}$. We could also assign different agents different types and make the distribution of wages depend on the types. These complications will only expand our state space, but the message of the paper will remain unchanged.

- To solve the simplest model presented by the above dynamic program, notice that our state space is defined by the vector $\left(l_{t-1}, \tau_{t}, w_{t-1}^{l_{t-1}}, s_{t-1}, N_{t-1}^{r}, \lambda_{t}\right)$. Given last period's subsidy $s_{t-1}=\left(s_{t-1}^{r}, s_{t-1}^{u}\right)$ in both sectors, last period's population distribution $\left(N_{t-1}^{r}, N_{t-1}^{u}\right)$, and this period's belief about $\left(\theta^{r}, \theta^{u}\right)$, defined by $\left(\lambda_{t}^{r}, \lambda_{t}^{u}\right)$, the agent chooses $l_{t}$ and consumes whatever is left of the wage and subsidy less the 
travelling cost $\tau_{t}$ if any travel is required in this period. The person works in the chosen sector, and then is informed of her wage, the subsidy levels for period $t$, and the population distribution in that period. Based on that information, the agent uses Bayes' rule to update her beliefs about the $\theta$ 's, and proceeds to observe $\tau_{t+1}$ and choose $l_{t+1}$, and so on.

- It is clear that the dynamic program defined above has a bounded reward function $E[u()$.$] , a finite action space \{r, u\}$, and a weakly continuous state transition kernel (due to the well known continuity of the Bayes updating map; see Easley and Kiefer (1988) or El-Gamal and Sundaram (1993) for details). Hence, by a well known result of Maitra (1968), the value function written below is well defined, and allows a measurable optimal selection (migration rule).

The Bellman's equation for that simple dynamic program is defined by:

$$
\begin{gathered}
v\left(l_{t-1}, \tau_{t}, w_{t-1}^{l_{t-1}}, s_{t-1}^{r}, s_{t-1}^{u}, N_{t-1}^{r}, \lambda_{t}\right)= \\
\max _{l_{t}} u\left(l_{t-1}\left(w_{t-1}^{r}+s_{t-1}^{r}\right)+\left(1-l_{t-1}\right)\left(w_{t-1}^{u}+s_{t-1}^{u}\right)-\tau_{t}\left|l_{t}-l_{t-1}\right|\right)+ \\
\int_{\Theta^{r}} \int_{\Theta^{u}} \int_{W} \int_{W}\left[\beta v\left(l_{t}, \tau_{t}, w_{t}^{l_{t}}, s_{t-1}^{r}, s_{t-1}^{u}, N_{t-1}^{r}, \mathfrak{B}\left(\lambda_{t}^{l_{t}}, N_{t-1}^{l_{t}}, w_{t}^{l_{t}}, l_{t}\right)\right)\right] \\
F^{r}\left(d w_{t}^{r} ; \theta^{r}, N_{t-1}^{r}\right) F^{u}\left(d w_{t}^{u} ; \theta^{u}, N_{t-1}^{u}\right) \lambda^{r}\left(d \theta^{r}\right) \lambda^{u}\left(d \theta^{u}\right)
\end{gathered}
$$

which is recursively well defined by the unique fixed point of the above contraction mapping. The set of optimands defines our optimal migration rule.

In the next section, we shall solve for the micro dynamics of boundedly rational agents facing the problem that we have defined. In the following sections, the government will be assumed to observe the economy and have a welfare function which increases with the earnings of the agents and decreases with the budget deficit. The government will be allowed to monitor the migration of agents, and charge a pre-announced migration tax. After the migration season is over, the government fine-tunes the system by deciding on and distributing wage subsidies in the two sectors. The government knows the true values $\left(\theta^{r *}, \theta^{u *}\right)$. It is, on the other hand, ignorant of the agents' beliefs about the $\theta$ 's and has to learn about them through the agents' migration patterns. The government cannot identify different agents and keep any information about their histories and/or actual wage draws.

\section{Micro-Dynamics}

In this section, we define the optimal migration rule and then we use it to derive the micro stochastic dynamics. We start by defining the following events:

$$
E_{1}=\left\{\int_{\theta^{r}} \int_{W}\left[u\left(w+s_{-1}^{r}\right)+\beta v\left(\tau, w, s_{-1}^{r}, s_{-1}^{u}, N_{-1}^{r}, \mathfrak{B}\left(\lambda^{r}, N_{-1}^{r}, w, r\right)\right)\right] F^{r}\left(d w ; \theta^{r}, N_{-1}^{r}\right) \lambda^{r}\left(d \theta^{r}\right)\right.
$$




$$
\begin{aligned}
& \left.\geq \int_{\Theta^{u}} \int_{W}\left[u\left(w+s_{-1}^{u}-\tau\right)+\beta v\left(\tau, w, s_{-1}^{r}, s_{-1}^{u}, N_{-1}^{u}, \mathfrak{B}\left(\lambda^{u}, N_{-1}^{u}, w, u\right)\right)\right] F^{u}\left(d w ; \theta^{u}, N_{-1}^{u}\right) \lambda^{u}\left(d \theta^{u}\right)\right\} \\
& E_{2}=\left\{\int_{\Theta^{r}} \int_{W}\left[u\left(w+s_{-1}^{r}\right)+\beta v\left(\tau, w, s_{-1}^{r}, s_{-1}^{u}, N_{-1}^{r}, \mathfrak{B}\left(\lambda^{r}, N_{-1}^{r}, w, r\right)\right)\right] F^{r}\left(d w ; \theta^{r}, N_{-1}^{r}\right) \lambda^{r}\left(d \theta^{r}\right)\right. \\
& \left.<\int_{\Theta^{u}} \int_{W}\left[u\left(w+s_{-1}^{u}-\tau\right)+\beta v\left(\tau, w, s_{-1}^{r}, s_{-1}^{u}, N_{-1}^{u}, \mathfrak{B}\left(\lambda^{u}, N_{-1}^{u}, w, u\right)\right)\right] F^{u}\left(d w ; \theta^{u}, N_{-1}^{u}\right) \lambda^{u}\left(d \theta^{u}\right)\right\} \\
& E_{3}=\left\{\int_{\theta^{r}} \int_{W}\left[u\left(w+s_{-1}^{r}-\tau\right)+\beta v\left(\tau, w, s_{-1}^{r}, s_{-1}^{u}, N_{-1}^{r}, \mathfrak{B}\left(\lambda^{r}, N_{-1}^{r}, w, r\right)\right)\right] F^{r}\left(d w ; \theta^{r}, N_{-1}^{r}\right) \lambda^{r}\left(d \theta^{r}\right)\right. \\
& \left.>\int_{\Theta^{u}} \int_{W}\left[u\left(w+s_{-1}^{u}\right)+\beta v\left(\tau, w, s_{-1}^{r}, s_{-1}^{u}, N_{-1}^{u}, \mathfrak{B}\left(\lambda^{u}, N_{-1}^{u}, w, u\right)\right)\right] F^{u}\left(d w ; \theta^{u}, N_{-1}^{u}\right) \lambda^{u}\left(d \theta^{u}\right)\right\} \\
& E_{4}=\left\{\int_{\theta^{r}}\left[u\left(w+s_{-1}^{r}-\tau\right)+\beta v\left(\tau, w, s_{-1}^{r}, s_{-1}^{u}, N_{-1}^{r}, \mathfrak{B}\left(\lambda^{r}, N_{-1}^{r}, w, r\right)\right)\right] F^{r}\left(d w ; \theta^{r}, N_{-1}^{r}\right) \lambda^{r}\left(d \theta^{r}\right)\right. \\
& \left.\leq \int_{\Theta^{u}} \int_{W}\left[u\left(w+s_{-1}^{u}\right)+\beta v\left(\tau, w, s_{-1}^{r}, s_{-1}^{u}, N_{-1}^{u}, \mathfrak{B}\left(\lambda^{u}, N_{-1}^{u}, w, u\right)\right)\right] F^{u}\left(d w ; \theta^{u}, N_{-1}^{u}\right) \lambda^{u}\left(d \theta^{u}\right)\right\}
\end{aligned}
$$

The optimal migration rule is then described by the following table:

\begin{tabular}{|c|c|c|}
\hline \multicolumn{3}{|c|}{ Table 1 } \\
\hline \hline \multicolumn{3}{|c|}{ Optimal Migration Rule } \\
\hline \hline Location of origin & Event occurs & Location of destination \\
\hline \hline $\mathrm{r}$ & E1 & $\mathrm{r}$ \\
\hline $\mathrm{r}$ & E2 & $\mathrm{u}$ \\
\hline $\mathrm{u}$ & E3 & $\mathrm{r}$ \\
\hline $\mathrm{u}$ & E4 & $\mathrm{u}$ \\
\hline
\end{tabular}

Given the above derived optimal migration rules, we can directly derive the probability transition matrix (from the government's point of view) for a given individual with a known belief $\lambda=\left(\lambda^{r}, \lambda^{u}\right)$, and given the previous period's data $N_{t-1}^{r}, N_{t-1}^{u}, s_{t-1}^{r}, s_{t-1}^{u}$, and the current migration tax $\tau_{t}$. Define the sets of beliefs (where $\mathfrak{P}($.$) is the space of$ probability measures on its argument):

$$
\begin{aligned}
& A_{1}=\left\{\lambda \in \mathfrak{P}\left(\Theta^{r}\right) \times \mathfrak{P}\left(\Theta^{u}\right): E_{1} \text { occurs }\right\} \\
& A_{2}=\left\{\lambda \in \mathfrak{P}\left(\Theta^{r}\right) \times \mathfrak{P}\left(\Theta^{u}\right): E_{2} \text { occurs }\right\} \\
& A_{3}=\left\{\lambda \in \mathfrak{P}\left(\Theta^{r}\right) \times \mathfrak{P}\left(\Theta^{u}\right): E_{3} \text { occurs }\right\} \\
& A_{4}=\left\{\lambda \in \mathfrak{P}\left(\Theta^{r}\right) \times \mathfrak{P}\left(\Theta^{u}\right): E_{4} \text { occurs }\right\}
\end{aligned}
$$


Then the transition Probability matrix

$$
Q_{\lambda, N_{-1}, s_{-1}, \tau}=\left(\begin{array}{ll}
q_{r r}^{\lambda, N_{-1}, s_{-1}, \tau} & q_{r u}^{\lambda, N_{-1}, s_{-1}, \tau} \\
q_{u r}^{\lambda, N_{-1}, s_{-1}, \tau} & q_{u u}^{\lambda, N_{-1}, s_{-1}, \tau}
\end{array}\right)
$$

is simply defined by:

$$
\begin{aligned}
& q_{r r}^{\lambda, N_{-1}, s_{-1}, \tau}=\int_{\left\{w^{r}: \mathbb{B}\left(\lambda^{r}, N_{-1}^{r}, w^{r}, l\right) \in A 1\right\}} F^{r}\left(d w^{r}, \theta^{r *}, N_{-1}^{r}\right)=1-q_{r u}^{\lambda, N_{-1}, s_{-1}, \tau} \\
& q_{u r}^{\lambda, N_{-1}, s_{-1}, \tau}=\int_{\left\{w^{u}: \mathbb{B}\left(\lambda^{u}, N_{-1}^{u}, w^{u}, l\right) \in A 3\right\}} F^{u}\left(d w^{u}, \theta^{u *}, N_{-1}^{u}\right)=1-q_{u u}^{\lambda, N_{-1}, s_{-1}, \tau}
\end{aligned}
$$

where $\left(\theta^{r *}, \theta^{u *}\right)$ are the true values of $\left(\theta^{r}, \theta^{u}\right)$ known to the government.

\section{Aggregate Dynamics}

The probability transition matrix for each individual given her own history and belief is fully defined by the probability transition matrix $Q$ derived in the previous section. For the government who knows the true values of $\theta^{r}$ and $\theta^{u}$, this is the building block for working towards an optimal subsidy and tax policy. We assume that the actual wage values observed by the agents as well as their initial beliefs are private knowledge that is not available to the government.

As a starting point, let's assume that at some time period $t$, the government's belief about the beliefs $\lambda^{r}$ and $\lambda^{u}$ of a typical agent is described by $\mu_{t}=\left(\mu_{t}^{r r}, \mu_{t}^{r u}, \mu_{t}^{u r}, \mu_{t}^{u u}\right)$, where $\mu_{t}^{i j}$ is the government's belief in period $t$ about the $\lambda_{t}^{j}$ for a randomly chosen agent in sector $i$; for $i=r, u$, and $j=r, u$. In what follows, we shall suppress the dependence of the transition probabilities on $s_{-1}$ and $\tau$ in the notation, but that dependence should be remembered. We can then define the aggregate transition probability from the government's point of view when it has belief $\mu_{t}$ by:

$$
\begin{gathered}
T_{n, m}^{\mu_{t}}=\operatorname{Pr}_{\mu_{\mathrm{t}}}\left\{N_{t+1}^{r}=m \mid N_{t}^{r}=n\right\} \\
=\frac{\sum_{i=0}^{n} \operatorname{Pr}_{\mu_{\mathrm{t}}}\{i \text { individuals } r \rightarrow u,(m-n+i) \text { individuals } u \rightarrow r, \text { the rest remain }\}}{\operatorname{Pr}_{\mu_{t}}\left\{N_{t}^{r}=n\right\}} \\
=\sum_{i=0}^{n}\left[\left(\int_{\mathfrak{P}\left(\Theta^{r}\right) \mathfrak{P}\left(\Theta^{u}\right)} \int_{r u}^{\lambda^{r}, \lambda^{u}} \mu_{t}^{r r}\left(d \lambda^{r}\right) \mu_{t}^{r u}\left(d \lambda^{u}\right)\right)^{i}\right. \\
\times\left(\int_{\mathfrak{P}\left(\Theta^{r}\right) \mathfrak{P}\left(\Theta^{u}\right)} q_{r_{r}^{r}, \lambda^{u}} \mu_{t}^{r r}\left(d \lambda^{r}\right) \mu_{t}^{r u}\left(d \lambda^{u}\right)\right)^{n-i}
\end{gathered}
$$




$$
\begin{gathered}
\times\left(\int_{\mathfrak{P}\left(\Theta^{r}\right) \mathfrak{P}\left(\Theta^{u}\right)} q_{u r}^{\lambda^{r}, \lambda^{u}} \mu_{t}^{u r}\left(d \lambda^{r}\right) \mu_{t}^{u u}\left(d \lambda^{u}\right)\right)^{m-n+i} \\
\left.\times\left(\int_{\mathfrak{P}\left(\Theta^{r}\right) \mathfrak{P}\left(\Theta^{u}\right)} q_{u u^{\lambda^{r}, \lambda^{u}}} \mu_{t}^{u r}\left(d \lambda^{r}\right) \mu_{t}^{u u}\left(d \lambda^{u}\right)\right)^{N-m-i}\right] / \operatorname{Pr}_{\mu_{t}}\left\{N_{t}^{r}=n\right\}
\end{gathered}
$$

Where $k \rightarrow l$ stands for migrating from sector $k$ to sector $l$. The collection of these terms yields the aggregate population transition matrix:

$$
T^{\mu_{t}}=\left(\begin{array}{ccc}
T_{00}^{\mu_{t}} & \ldots & T_{0 N}^{\mu_{t}} \\
\vdots & \ddots & \vdots \\
T_{N 0}^{\mu_{t}} & \ldots & T_{N N}^{\mu_{t}}
\end{array}\right)
$$

where the belief $\mu_{t}$ is given. Starting with some initial belief $\mu_{0}$, it only remains to specify the rule for updating $\mu_{t}$ into $\mu_{t+1}$.

Let the government have current belief $\mu_{t}$, decide on the migration tax $\tau_{t}$, and then observe the migration for period $t$. Let $N_{t-1}^{r}=n$ and $N_{t}^{r}=m$, and let $k$ agents migrate from $r$ to $u$ (and hence $m-n+k$ migrate from $u$ to $r$ ), the government then updates its beliefs from $\mu_{t}$ to $\mu_{t+1}=\left(\mu_{t+1}^{r r}, \mu_{t+1}^{r u}, \mu_{t+1}^{u r}, \mu_{t+1}^{u u}\right)$, and then chooses the subsidy levels $s_{t}^{r}, s_{t}^{u}$ and the migration tax $\tau_{t+1}$. The updating rule from $\mu_{t}$ to $\mu_{t+1}$ is done in four steps:

Step 1 updates the government's belief about the typical $\lambda$ 's in both sectors before the actual migration in period $t$ took place. In other words it only takes care of updating based on the intentions to migrate.

Step 2 updates taking into consideration the government's knowledge of the true $\left(\theta^{r *}, \theta^{u *}\right)$, and knowing that the $\lambda$ 's will have to change once the wages and population frequencies are observed by the agents. The first two steps still do not take into consideration the mixing up of the populations from the two sectors via migration, and the resulting contamination of their beliefs.

Step 3 computes the government's beliefs about the typical belief of those from the two populations who will choose to migrate, and those who choose not to.

Step 4 will add the contamination of the migrants' beliefs to the non-migants' and achieves the next period's beliefs $\mu_{t+1}$.

In the following, let $A \subset \mathfrak{P}\left(\Theta^{r}\right)$ and $B \subset \mathfrak{P}\left(\Theta^{u}\right)$.

Step1:

In this step, the $\mu_{t}^{i j}$ 's are updated to the $S 1^{i j}$ 's which take into consideration what the $\mu_{t}^{i j}$ should have been had the government known what the next period population distribution will be. 
$S 1^{r r}(A)=\frac{\left(\int_{A} \int_{\left(\Theta^{u}\right)} q_{r u}^{\lambda^{r}, \lambda^{u}} \mu_{t}^{r r}\left(d \lambda^{r}\right) \mu_{t}^{r u}\left(d \lambda^{u}\right)\right)^{k}\left(\int_{A \mathfrak{P}\left(\Theta^{u}\right)} q_{r r}^{\lambda_{r}^{r}, \lambda^{u}} \mu_{t}^{r r}\left(d \lambda^{r}\right) \mu_{t}^{r u}\left(d \lambda^{u}\right)\right)^{n-k} \mu_{t}^{r r}(A)}{\left(\int_{\mathfrak{P}\left(\Theta^{r}\right)} \int_{\left(\Theta^{u}\right)} q_{r u}^{\lambda^{r}, \lambda^{u}} \mu_{t}^{r r}\left(d \lambda^{r}\right) \mu_{t}^{r u}\left(d \lambda^{u}\right)\right)^{k}\left(\int_{\mathfrak{P}\left(\Theta^{r}\right) \mathfrak{P}\left(\Theta^{u}\right)} q_{r r}^{\lambda_{r}^{r}, \lambda^{u}} \mu_{t}^{r r}\left(d \lambda^{r}\right) \mu_{t}^{r u}\left(d \lambda^{u}\right)\right)^{n-k}}$

$S 1^{r u}(B)=\frac{\left(\int_{\mathfrak{P}\left(\Theta^{r}\right)} \int_{B} q_{r u}^{\lambda^{r}, \lambda^{u}} \mu_{t}^{r r}\left(d \lambda^{r}\right) \mu_{t}^{r u}\left(d \lambda^{u}\right)\right)^{k}\left(\int_{\mathfrak{P}\left(\Theta^{r}\right)} \int_{B} q_{r r}^{\lambda^{r}, \lambda^{u}} \mu_{t}^{r u}\left(d \lambda^{r}\right) \mu_{t}^{r u}\left(d \lambda^{u}\right)\right)^{n-k} \mu_{t}^{r u}(B)}{\left(\int_{\mathfrak{P}\left(\Theta^{r}\right) \mathfrak{P}\left(\Theta^{u}\right)} q_{r u}^{\lambda_{r u}^{r}, \lambda^{u}} \mu_{t}^{r r}\left(d \lambda^{r}\right) \mu_{t}^{r u}\left(d \lambda^{u}\right)\right)^{k}\left(\int_{\mathfrak{P}\left(\Theta^{r}\right) \mathfrak{P}\left(\Theta^{u}\right)} q_{r r}^{\lambda_{r r}^{r}, \lambda^{u}} \mu_{t}^{r r}\left(d \lambda^{r}\right) \mu_{t}^{r u}\left(d \lambda^{u}\right)\right)^{n-k}}$

$S 1^{u r}(A)=\frac{\left(\int_{A \mathfrak{P}\left(\Theta^{u}\right)} q_{u^{r}}^{\lambda^{r}, \lambda^{u}} \mu_{t}^{u r}\left(d \lambda^{r}\right) \mu_{t}^{u u}\left(d \lambda^{u}\right)\right)^{m-n+k}\left(\int_{A \mathfrak{P}\left(\Theta^{u}\right)} q_{u u^{\lambda^{r}, \lambda^{u}}} \mu_{t}^{u r}\left(d \lambda^{r}\right) \mu_{t}^{u u}\left(d \lambda^{u}\right)\right)^{N-m-k} \mu_{t}^{u r}(A)}{\left(\int_{\mathfrak{P}\left(\Theta^{r}\right)} \int_{\left(\Theta^{u}\right)} q_{u r}^{\lambda_{u}, \lambda^{u}} \mu_{t}^{u r}\left(d \lambda^{r}\right) \mu_{t}^{u u}\left(d \lambda^{u}\right)\right)^{k}\left(\int_{\mathfrak{P}\left(\Theta^{r}\right) \mathfrak{P}\left(\Theta^{u}\right)} q_{u u^{\lambda^{r}}, \lambda^{u}} \mu_{t}^{u r}\left(d \lambda^{r}\right) \mu_{t}^{u u}\left(d \lambda^{u}\right)\right)^{n-k}}$

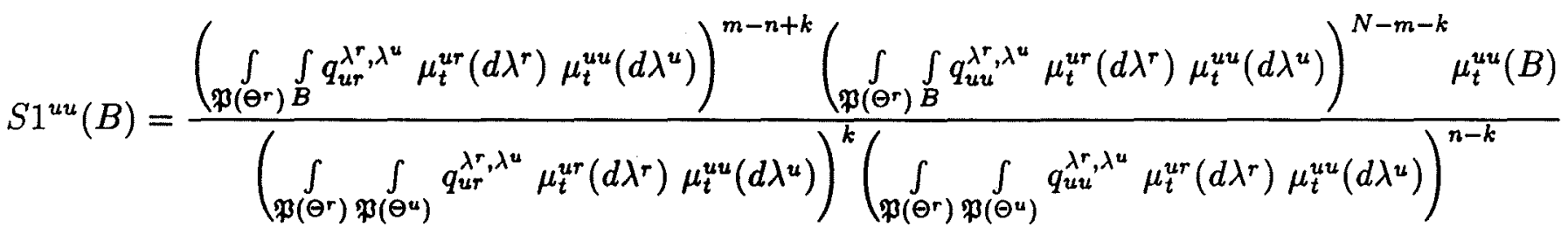

\section{Step2:}

In this step, we take the $S 1^{i j}$ 's and update them by taking into consideration the possible wage draws that could have occurred (remember the government knows the true $\left.\left(\theta^{r *}, \theta^{u *}\right)\right)$, and how the agents are expected to change their beliefs accordingly.

$$
\begin{gathered}
S 2^{r r}(A)=\int_{\mathfrak{P}\left(\Theta^{r}\right)} \int_{\left\{w^{r}: \mathfrak{B}\left(\lambda^{r}, n, w^{r}, r\right) \in A\right\}} F^{r}\left(d w^{r}, \theta^{r *}, n\right) S 1^{r r}\left(d \lambda^{r}\right) \\
S 2^{r u}(B)=S 1^{r u}(B) \\
S 2^{u r}(A)=S 1^{u r}(A)
\end{gathered}
$$




$$
S 2^{u u}(B)=\int_{\mathfrak{P}\left(\Theta^{u}\right)} \int_{\left\{w^{u}: \mathfrak{B}\left(\lambda^{u}, n, w^{u}, u\right) \in B\right\}} F^{u}\left(d w^{u}, \theta^{u *}, n\right) S 1^{u u}\left(d \lambda^{u}\right)
$$

\section{Step 3:}

In this step, as in Step 1, we use Bayes' theorem. For instance, the first term $S 3_{r}^{r \rightarrow r}(A)$ stands for the probability that $\lambda^{r}$ will fall in the set $A$ for an individual who was in sector $r$, and decided to stay in sector $r$. We then use Bayes' theorem as follows:

$S 3_{r}^{r \rightarrow r}(A)=\operatorname{Pr}\left\{\lambda^{r} \in A \mid\right.$ agent stays in $\left.r\right\}=\frac{\operatorname{Pr}\left\{\text { agent stays in } r \mid \lambda^{r} \in A\right\} \times \operatorname{Pr}\left\{\lambda^{r} \in A\right\}}{\operatorname{Pr}\{\text { agent stays in } \mathbf{r}\}}$

Similarly, all the other terms $S 3_{k}^{i \rightarrow j}$ (.) can be derived as the government's belief regarding the distribution of beliefs about $\theta^{k}$ among the agents who migrated from sector $i$ to sector $j$ :

$$
\begin{aligned}
& S 3_{r}^{r \rightarrow r}(A)=\frac{\int_{A} \int_{\mathfrak{P}\left(\Theta^{u}\right)} q_{r r}^{\lambda^{r}, \lambda^{u}} S 2^{r r}\left(d \lambda^{r}\right) S 2^{r u}\left(d \lambda^{u}\right) \times S 2^{r r}(A)}{\int_{\mathfrak{P}\left(\Theta^{r}\right) \mathfrak{P}\left(\Theta^{u}\right)} q_{r r}^{\lambda^{r}, \lambda^{u}} S 2^{r r}\left(d \lambda^{r}\right) S 2^{r u}\left(d \lambda^{u}\right)} \\
& S 3_{r}^{r \rightarrow u}(A)=\frac{\int_{A} \int_{\mathfrak{P}\left(\Theta^{u}\right)} q_{r u}^{\lambda^{r}, \lambda^{u}} S 2^{r r}\left(d \lambda^{r}\right) S 2^{r u}\left(d \lambda^{u}\right) \times S 2^{r r}(A)}{\int_{\mathfrak{P}\left(\Theta^{r}\right) \mathfrak{P}\left(\Theta^{u}\right)} q_{r u}^{\lambda_{u}^{r}, \lambda^{u}} S 2^{r r}\left(d \lambda^{r}\right) S 2^{r u}\left(d \lambda^{u}\right)} \\
& S 3_{r}^{u \rightarrow r}(A)=\frac{\int_{A} \int_{\mathfrak{P}\left(\Theta^{u}\right)} q_{u r}^{\lambda^{r}, \lambda^{u}} S 2^{u r}\left(d \lambda^{r}\right) S 2^{u u}\left(d \lambda^{u}\right) \times S 2^{u r}(A)}{\int_{\mathfrak{P}\left(\Theta^{r}\right)} \int_{\mathfrak{P}\left(\Theta^{u}\right)} q^{\lambda_{u r}^{r}, \lambda^{u}} S 2^{u r}\left(d \lambda^{r}\right) S 2^{u u}\left(d \lambda^{u}\right)} \\
& S 3_{r}^{u \rightarrow u}(A)=\frac{\int_{A \mathfrak{P}\left(\Theta^{u}\right)} q_{u u}^{\lambda^{r}, \lambda^{u}} S 2^{u r}\left(d \lambda^{r}\right) S 2^{u u}\left(d \lambda^{u}\right) \times S 2^{u r}(A)}{\int_{\mathfrak{P}\left(\Theta^{r}\right)} \int_{\mathfrak{P}\left(\Theta^{u}\right)} q_{u u^{\lambda^{r}, \lambda^{u}}} S 2^{u r}\left(d \lambda^{r}\right) S 2^{u u}\left(d \lambda^{u}\right)} \\
& S 3_{u}^{r \rightarrow r}(B)=\frac{\int_{\mathfrak{P}\left(\Theta^{r}\right)} \int_{B} q_{r r}^{\lambda^{r}, \lambda^{u}} S 2^{r r}\left(d \lambda^{r}\right) S 2^{r u}\left(d \lambda^{u}\right) \times S 2^{r u}(B)}{\int_{\mathfrak{P}\left(\Theta^{r}\right) \mathfrak{P}\left(\Theta^{u}\right)} q_{r r}^{\lambda^{r}, \lambda^{u}} S 2^{r r}\left(d \lambda^{r}\right) S 2^{r u}\left(d \lambda^{u}\right)}
\end{aligned}
$$




$$
\begin{aligned}
& S 3_{u}^{r \rightarrow u}(B)=\frac{\int_{\mathfrak{P}\left(\Theta^{r}\right)} \int_{B} q_{r u}^{\lambda^{r}, \lambda^{u}} S 2^{r r}\left(d \lambda^{r}\right) S 2^{r u}\left(d \lambda^{u}\right) \times S 2^{r u}(B)}{\int_{\mathfrak{P}\left(\Theta^{r}\right) \mathfrak{P}\left(\Theta^{u}\right)} q_{r u}^{\lambda^{r}, \lambda^{u}} S 2^{r r}\left(d \lambda^{r}\right) S 2^{r u}\left(d \lambda^{u}\right)} \\
& S 3_{u}^{u \rightarrow r}(B)=\frac{\int_{\mathfrak{P}\left(\Theta^{r}\right)} \int_{B} q_{u r}^{\lambda^{r}, \lambda^{u}} S 2^{u r}\left(d \lambda^{r}\right) S 2^{u u}\left(d \lambda^{u}\right) \times S 2^{u u}(B)}{\int_{\mathfrak{P}\left(\Theta^{r}\right) \mathfrak{P}\left(\Theta^{u}\right)} q_{u r}^{\lambda_{r}^{r}, \lambda^{u}} S 2^{u r}\left(d \lambda^{r}\right) S 2^{u u}\left(d \lambda^{u}\right)} \\
& S 3_{u}^{u \rightarrow u}(B)=\frac{\int_{\mathfrak{P}\left(\Theta^{r}\right)} \int_{B} q_{u u}^{\lambda^{r}, \lambda^{u}} S 2^{u r}\left(d \lambda^{r}\right) S 2^{u u}\left(d \lambda^{u}\right) \times S 2^{u u}(B)}{\int_{\mathfrak{P}\left(\Theta^{r}\right) \mathfrak{P}\left(\Theta^{u}\right)} q_{u u^{\lambda^{r}}} \lambda^{u} S 2^{u r}\left(d \lambda^{r}\right) S 2^{u u}\left(d \lambda^{u}\right)}
\end{aligned}
$$

\section{Step 4:}

Now, we are ready to compute the beliefs $\mu_{t+1}$ with the contaminations of the beliefs of those who decided to stay behind by those who decided to migrate.

$$
\begin{aligned}
& \mu_{t+1}^{r r}(A)=\frac{n-k}{m} S 3_{r}^{r \rightarrow r}(A)+\frac{m-n+k}{m} S 3_{r}^{u \rightarrow r}(A) \\
& \mu_{t+1}^{r u}(B)=\frac{n-k}{m} S 3_{u}^{r \rightarrow r}(B)+\frac{m-n+k}{m} S 3_{u}^{u \rightarrow r}(B) \\
& \mu_{t+1}^{u r}(A)=\frac{N-m-k}{N-m} S 3_{r}^{u \rightarrow u}(A)+\frac{k}{N-m} S 3_{r}^{r \rightarrow u}(A) \\
& \mu_{t+1}^{u u}(B)=\frac{N-m-k}{N-m} S 3_{u}^{u \rightarrow u}(B)+\frac{k}{N-m} S 3_{u}^{r \rightarrow u}(B)
\end{aligned}
$$

We summarize this entire updating rule by the notation:

$$
\mu_{t+1}=\mathfrak{B}^{\mu}\left(\mu_{t}, n, m, k\right)
$$




\section{The Government's Decision Problem}

Now, given the transition matrix $T^{\mu_{t}}$ and the updating rule from $\mu_{t}$ to $\mu_{t+1}$, the government's decision problem can be properly specified. Let the government's revenue from migration taxes in period $t$ be $R_{t}=\sum_{i=1}^{N} \tau_{t}\left|l_{t}^{i}-l_{t-1}^{i}\right|$. We assume that the government has a time-separable welfare function to maximize:

$$
\begin{gathered}
\max _{\left\{s_{t}^{r}, s_{t}^{u}, \tau_{t+1}\right\}} E_{0} \mathfrak{W}\left(\vec{w}_{0}+\vec{s}_{0}-\vec{m}_{0}, \vec{w}_{1}+\vec{s}_{1}-\vec{m}_{1}, \ldots\right) \\
=\max _{\left\{s_{t}^{r}, s_{t}^{u}, r_{t+1}\right\}} E_{0} \sum_{t=0}^{\infty} \delta^{t}\left(U\left(\vec{w}_{t}+\vec{s}_{t}-\vec{m}_{t}\right)+Q\left(R_{t}-N_{t}^{r} s_{t}^{r}+N_{t}^{u} s_{t}^{u}\right)\right)
\end{gathered}
$$

where $\vec{w}_{t}=\left(w_{t}^{1, r}, \ldots, w_{t}^{N_{t}^{r}, r}, w_{t}^{1, u}, \ldots, w_{t}^{N_{t}^{u}, u}\right), \vec{s}_{t}=\left(s_{t}^{r}, \ldots, s_{t}^{r}, s_{t}^{u}, \ldots, s_{t}^{u}\right)$ with $N_{t}^{r}$ of the first term and $N_{t}^{u}$ of the second, and $\vec{m}_{t}$ is a vector whose $i^{t h}$ element is $\tau_{t}\left|l_{t}^{i}-l_{t-1}^{i}\right|$. The utility function $U$ is assumed increasing in its arguments (each individual's consumption for each period), and the utility function $Q$ is assumed to be increasing in its arguments (the budget surplus).

The Government has as its control the wage subsidies $\left(s_{t}^{r}, s_{t}^{u}\right)$ to be distributed at the end of the current period, and the migration tax $\tau_{t+1}$ to be collected from agents who decide to migrate in $t+1$. The state variable is defined by the pair $\left(\mu_{t}, N_{t}^{r}\right)$. The optimal tax and subsidy problem can be written as follows:

$$
\begin{gathered}
\max _{\left\{s_{t}^{r}, s_{t}^{u}, \tau_{t+1}\right\}} E_{0} \sum_{t=0}^{\infty} \delta^{t}\left[\int_{W^{N_{t}^{r}}} \int_{W^{N_{t}^{u}}} U\left(\vec{w}_{t}+\vec{s}_{t}-\vec{m}_{t}\right) \prod_{i=1}^{N_{t}^{r}} F^{r}\left(d w^{i, r} ; \theta^{r *}, N_{t}^{r}\right) \prod_{j=1}^{N_{t}^{u}} F^{u}\left(d w^{j, u} ; \theta^{u *}, N_{t}^{u}\right)\right. \\
\left.+Q\left(R_{t}-N_{t}^{r} s_{t}^{r}-N_{t}^{u} s_{t}^{u}\right)\right]
\end{gathered}
$$

s.t.

$$
\begin{gathered}
\operatorname{Pr}\left\{N_{t+1}=m \mid N_{t}^{u}=n\right\}=T_{n m}^{\mu_{t}} \\
\mu_{t}=\mathfrak{B}^{\mu}\left(\mu_{t-1}, N_{t-1}^{r}, N_{t}^{r}\right)
\end{gathered}
$$

The value function for this problem is defined by:

$$
\begin{gathered}
V\left(\mu_{t}, N_{t}^{r}\right)=\max _{\left(s_{t}^{r}, s_{t}^{u}, \tau_{t+1}\right)}\left[\int_{W^{N_{t}^{r}}} \int_{W^{N_{t}^{u}}} E_{t} U\left(\vec{w}_{t}+\vec{s}_{t}-\vec{m}_{t}\right) \prod_{i=1}^{N_{t}^{r}} F^{r}\left(d w^{i, r} ; \theta^{r *}, N_{t}^{r}\right) \prod_{j=1}^{N_{t}^{u}} F^{u}\left(d w^{j, u} ; \theta^{u *}, N_{t}^{u}\right)\right. \\
\quad+Q\left(R_{t}-N_{t}^{r} s_{t}^{r}-N_{t}^{u} s_{t}^{u}\right) \\
+\delta \sum_{k=0}^{N_{t}^{r}} \sum_{l=0}^{N-N_{t}^{r}} \operatorname{Pr}\{\text { exactly } k \text { migrate } r \rightarrow u, \text { and } l \text { migrate } u \rightarrow r\} \\
\left.\times V\left(\mathfrak{B}^{\mu}\left(\mu_{t}, N_{t}^{r}, N_{t}^{r}+l-k, k\right), N_{t}^{r}+l-k\right)\right]
\end{gathered}
$$


is recursively well defined and admits a measurable optimal subsidy and tax function $\left(N_{t}^{r}, \mu_{t}\right) \mapsto\left(s_{t}^{r}, s_{t}^{u}, \tau_{t+1}\right)$.

\section{Remarks}

- The existence of the value function $V$, and the optimal subsidy and tax function, again follows since the government's dynamic program has a metric state space with a weakly continuous transition kernel (due to the continuity of steps 1 through 4 of Bayesian updating from $\mu_{t}$ to $\left.\mu_{t+1}\right)$, and a compact control space $[0, \bar{s}] \times[0, \bar{\tau}]$. Again see Easley and Kiefer (1988), or El-Gamal and Sundaram (1993) for detailed proofs of technically identical results.

- If we assume that the government observes the actual empirical distribution of wages for the agents, then $S 2$ can be computed much more simply without having to integrate over all wages that could have been observed.

- If there is only one realized wage that is paid to all the workers in a given sector, then the government's decision problem will be much simpler with the vectors $\vec{w}_{t}$ containing only two distinct terms $w_{t}^{\tau}$ and $w_{t}^{u}$.

- We could have chosen to constrain the government to commit to $\left(s_{t}^{\tau}, s_{t}^{u}\right)$ at the same time it chooses $\tau_{t}$, i.e. before the agents choose whether or not to migrate. However, this would limit the government's ability to correct instantaneous welfare losses due to errors in its choice of $\tau_{t}$ resulting in over- or under-migration and a poor distribution of wages. The choice of the subsidies, however, also influences the agents' beliefs and their migration patterns in the future (which is implicit in the government's dynamic program), and hence is not a costless fine-tuning parameter to maximize instantaneous welfare.

- The migration tax can serve the purpose of migration restriction in the original Harris-Todaro model. A sufficiently high migration tax can make the probability that any agent can afford to pay it (by getting a sufficiently high wage draw) as small as the government wishes. In the Harris-Todaro framework where the support of $F^{r}\left(., \theta^{r *}, N^{r}\right)$ is the two points zero and the minimum wage $\underline{\mathrm{w}}$, setting $\tau_{t}>\underline{\mathrm{w}}$ will be sufficient to stop migration from $r$ to $u$.

- In the classical Harris-Todaro model, and its offspring, the problem is usually seen as one of unemployment in the urban sector. The setting there is static, but if we see it as the setting for each period of our dynamic model, it would make the distribution $F^{r}\left(., \theta^{r}, N^{r}\right)$ degenerate at some rural wage $w^{r}\left(N^{r}\right)$, and the distribution $F^{u}\left(., \theta^{u}, N^{u}\right)$ would have two atoms at 0 (unemployment), and $w^{u}\left(N^{u}\right)$ which is bound to be greater than or equal to some minimum wage w. Notice that full information is available to the workers in this framework (the $\theta$ 's do not influence the wage distribution in either sector). This framework is equivalent to all agents having correct degenerate beliefs $\lambda^{r}=\theta^{r *}$, and $\lambda^{u}=\theta^{u *}$. In that framework, the instantaneous welfare effects of the subsidy and migration tax (equalling 0 , or a 
number larger than $w^{r}\left(N^{r}\right)$, and hence serving as a tool for migration restriction) are identical to those of the traditional Harris-Todaro studies (where $W(),. F^{r}($. and $F^{u}($.$) are chosen appropriately). In our (dynamic) framework, however, the$ effects of policies on beliefs (and hence on future migration) have to be taken into consideration.

\section{Comparative Dynamics and Policy Analysis}

In this section, we introduce two rather inoccuous simplifying assumptions, and study the effect of the parameters of the model on the micro and macro-dynamics of migration, and the optimal policy variables. We shall use $i$ and $j$ for generic reference to the sectors $r$ and $u$. The two assumptions are:

(A.1) Let $\theta \in \mathbb{R}$, and let $F^{i}(d w ; \theta, N)$ stochastically dominate $F^{i}(d w ; \phi, N)$ for $\theta>\phi$, for $i=r, u$.

(A.2) Let the agent's utility function $u($.$) , and the government's utility function U()+$. $Q($.$) be strictly concave.$

The assumption (A.1) allows us to have a complete ordering of potential distributions of wages in the two sectors which allows us to introduce the notion of monotonicity of various variables of interest as a function of the agent beliefs. Assumption (A.2) insures the single-valuedness (and hence continuity) of the optimal policy for the agent's as well as the government's problem. We are now ready to analyze the effect of the various parameters of our model on the dynamics and policy variables under (A.1) and (A.2).

First, we establish some monotonicity properties for the micro and macro-dynamics of our model:

- For a given individual residing in sector $i$, if for a fixed $\lambda^{i}\left(d \theta^{i}\right)=\lambda^{i}\left(d \theta^{i}\right)$, and for fixed population distributions and goverment policy variables, $\lambda^{\prime j}\left(d \theta^{j}\right)$ stochastically dominates $\lambda^{j}\left(d \theta^{j}\right)$, then the probability of migration from $i$ to $j, q_{i, j}^{\lambda^{\prime}, N_{-1}, s_{-1}, \tau}>$ $q_{i, j}^{\lambda, N_{-1}, s_{-1}, \tau}$. This follows immediately from the definition of events $E_{1}-E_{4}$ which defined the agent's optinal migration rule in section 3 . As the probability of staying in $i$ is one minus the probability of migrating to $j$, the probability of staying in $i$ decreases as the belief on $\theta^{j}$ increases (in the sense of stochastic dominance). If the individual resided in sector $j$, then the probability of staying in $j$ increases, and the probability of migrating to $i$ declines.

- Similarly, if $\lambda^{\prime i}($.$) stochastically dominates \lambda^{i}($.$) , while everything else stays fixed,$ the probability of migration from $j$ to $i$ and the probability of staying in $i$ increase, while the probability of staying in $j$ and the probability of migrating from $i$ to $j$ decrease. This establishes the monotonicity of the individual migrant's migration probability in that agent's beliefs. 
- Holding everything else constant, if $s_{t}^{i}$ increases, the probability of migration from $j$ to $i$ and the probability of staying in $i$ increase, while the probability of migrating from $i$ to $j$ and the probability of staying in $j$ decrease. Again, this can be seen by inspecting events $E_{1}-E_{4}$ of section 3 . Notice that $s^{i}$ only enters the value function additively to $w^{i}$. Hence, given the agent always believes that $s_{t+1}^{i}=s_{t}^{i}$, an increase in $s_{t}^{i}$ has the same effect on the values of staying and migrating as an increase in $\lambda^{i}($.$) (in the sense of stochastic dominance). By the previous argument, the$ monotonicity of the migration properties in the subsidy levels is also established.

- If $\tau$ increases, the probability of migration in either direction decreases, and the probability of staying in the individual's current sector increases. This again can be seen from events $E_{1}-E_{4}$ where $\tau$ enters as a one-time shock to the individual's value function in the event of migration. The effect of inhibiting migration is further multiplied by the fact that the individual expects $\tau$ to stay at its high level, so if after migration, the individual regrets the previous period's decision and decides to migrate again, she will have to pay the same (higher) tax again.

- Finally, as $\beta$ increases, the probability of migration increases. This follows immediately since the payoff from migration is always weighted by the discount factor $\beta$ whereas the migration tax has to be payed instantly (and hence affects current utility).

So far, we have established the monotonicity properties of the individual migration rules (and hence the macro-dynamics as well) in the policy variables $s_{t}^{i}, s_{t}^{j}$ and $\tau_{t+1}$. We now establish the possibility of the need for goverment intervention, regardless of how long the economy has been running. We establish the possibility that agents may refrain from migration when it is advantageous to them simply because of erroneous beliefs.

- In the absence of government intervention, assume that there exists a $\hat{\theta}^{j}$ such that $F^{i}\left(d w ; \theta^{i}, N\right)$ stochastically dominates $F^{j}\left(d w ; \hat{\theta}^{j}, N^{\prime}\right)$ for all $\theta^{i}, N, N^{\prime}$. Then there exists a belief $\lambda=\left(\lambda^{i}, \lambda^{j}\right)$ with $\lambda^{j}$ sufficiently concentrated around $\hat{\theta}^{j}$ such that an agent with that belief will always migrate from $j$ to $i$, and will never migrate back from $i$ to $j$, regardless of the sequence of wage draws and migration patterns that person observes. This follows directly from the weak continuity of the individual's value function in her belief, together with the continuity of the Bayes updating map. Our individual will immediately want to migrate to $i$ if she happens to be in $j$, getting at most one observation on $\theta^{j}$, which is not sufficient to move her belief far enough from $\hat{\theta}^{j}$ to warrant experimenting by migrating back to $j$, regardless of how bad the situation may be in $i$.

The government intervention can in our extreme case, as well as more moderate cases, influence the decision of subjects to migrate, learn, and in the long run, be sufficiently informed to obtain a socially optimal distribution. In the special case where $\hat{\theta}^{j}$ made sector $j$ look extremely unattractive to some agents, the government can increase $s_{t}^{j}$ 
sufficiently to shift the distribution of $w^{j}$ up and invite the workers to sample enough data points to get their beliefs closer to the correct parameter $\theta^{j *}$. Of course, the cost of enforcing that learning (in terms of the budget deficit that needs to be generated) may be too high to make it worth pursuing. Instead of making further restrictive assumptions and analyzing how the government's optimal policy will vary with the current population distribution $N_{t}^{r}$ and beliefs $\mu_{t}$, we argue for solving the government's dynamic program in any case of interest, and studying the optimal policy rule for that case. The following section introduces a numerical parametrization of the model, and solves the various components of the agents' and government's problems.

\section{$7 \quad$ Numerical Example}

In this section, we shall solve a simple parametric example of our model. The framework of our example will be as close as one can get to the Harris-Todaro world without losing the uncertainty and dynamic components of our model. We let $\Theta^{r}=\{1,2\}$ and $\Theta^{u}=$ $\{4,8\}$. Beliefs on $\theta^{r}$ and $\theta^{u}$ are simply represented by real numbers $\lambda^{r}=\operatorname{Pr}\left\{\theta^{r}=1\right\}$ and $\lambda^{u}=\operatorname{Pr}\left\{\theta^{u}=4\right\}$. We assume that we have a population $N=100$. The discount factor for our agents is $\beta=0.25$, and their utility function is $u(c)=\sqrt{c}$.

To mimic of the Harris-Todaro world, let the wage in the rural sector be determined in each period by

$$
w_{t}^{r}=\frac{1}{N_{t}^{r}} \text { if } \theta^{r}=1
$$

and

$$
w_{t}^{r}= \begin{cases}\frac{1}{N_{t}^{r}}, & \text { with prob. } 1 / 2 ; \\ \frac{2}{N_{t}^{r}}, & \text { with prob. } 1 / 2\end{cases}
$$

if $\theta^{r}=2$. All workers in the rural sector receive the same wage. The true value of $\theta^{r}$ is 1 , and hence, the wages are a deterministic function of the population, but the agents have beliefs that it may be a stochastic function. Notice that had $\theta^{r}$ been equal to 2 , one draw of the high wage would have been enough to learn the true parameter in sector $r$ instantly, but in our example, all non-zero beliefs will still be positive after observing the wage.

In the urban sector, there is a maximum of 50 jobs available, and any extra workers living in that sector are unemployed. As in the Harris-Todaro model, the total population of the urban sector $N_{t}^{u}$ is in each period randomly allocated with equal probability to be employed or unemployed. For those who are employed, the wage is determined by

$$
w_{t}^{\text {uemp }}=\frac{4}{\min \left(50, N_{t}^{u}\right)} \text { if } \theta^{u}=4
$$

and

$$
w_{t}^{\text {uemp }}= \begin{cases}\frac{4}{\min \left(50, N_{t}^{(1)}\right.}, & \text { with prob. } 1 / 2 ; \\ \frac{8}{\min \left(50, N_{t}^{*}\right)}, & \text { with prob. } 1 / 2\end{cases}
$$


if $\theta^{u}=8$. Each worker is employed with probability $\min \left(1,50 / N_{t}^{u}\right)$, and all employed workers get the same wage. The true value of $\theta^{u}$ is 4 . Notice again that this makes the expected wage in the urban sector (probability of getting employment times the urban wage $w_{t}^{\text {uemp }}$ ) a deterministic function of $N_{t}^{u}$, but the workers have beliefs that there is a chance of getting twice that much if $\theta^{u}=8$. Again given the current configuration, total learning of the true value of $\theta^{u}$ will not occur in finite time.

\subsection{The agent's problem and micro-dynamics}

Under no government intervention, $s_{-1}^{r}=s_{-1}^{u}=\tau=0$. Now, for the current period, let $N^{r}=30$ (and $N^{u}=70$ ), then we can solve (by iterating on the Bellman equation) for the worker's value function (of section 2) for being in the rural sector, being in the urban sector and employed, or being in the urban sector and unemployed during this period. Those three value functions are shown in Figures 2, 3, and 4 respectively. The value functions were obtained by iterating on the contraction mapping on a grid of $21 \times 21$ points until the sum of the absolute maximum difference between the iterates of the three value functions was smaller than $5 \times 10^{-10}$. This target was reached after 19 iterations. 


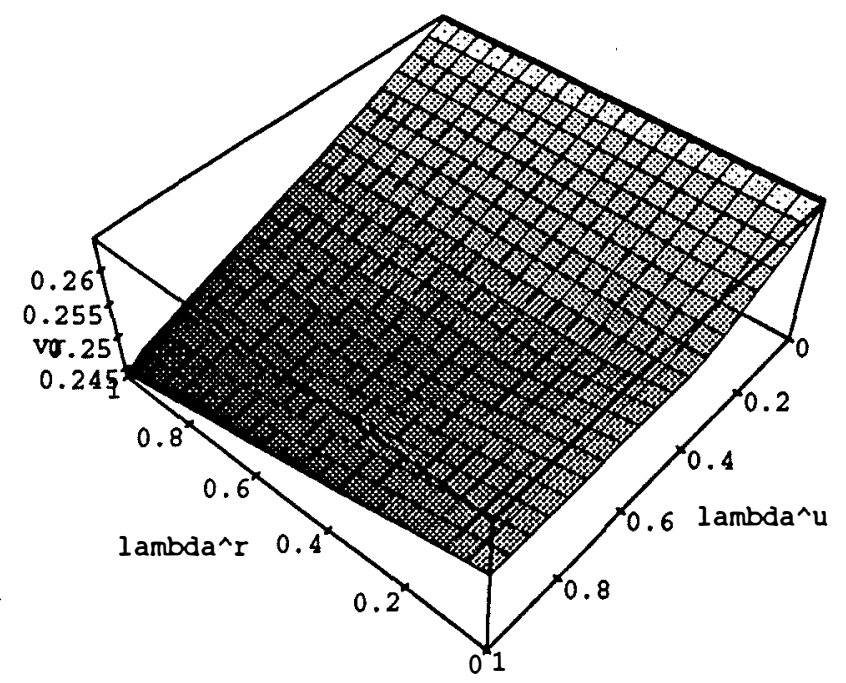

Figure 2: Value function for an agent in sector $r$

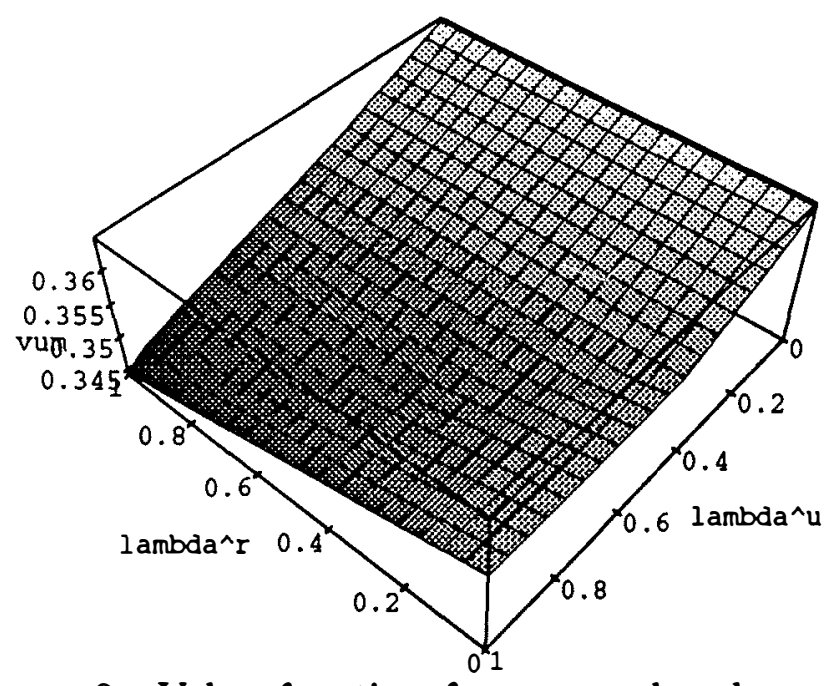

Figure 3: Value function for an employed agent in sector $u$

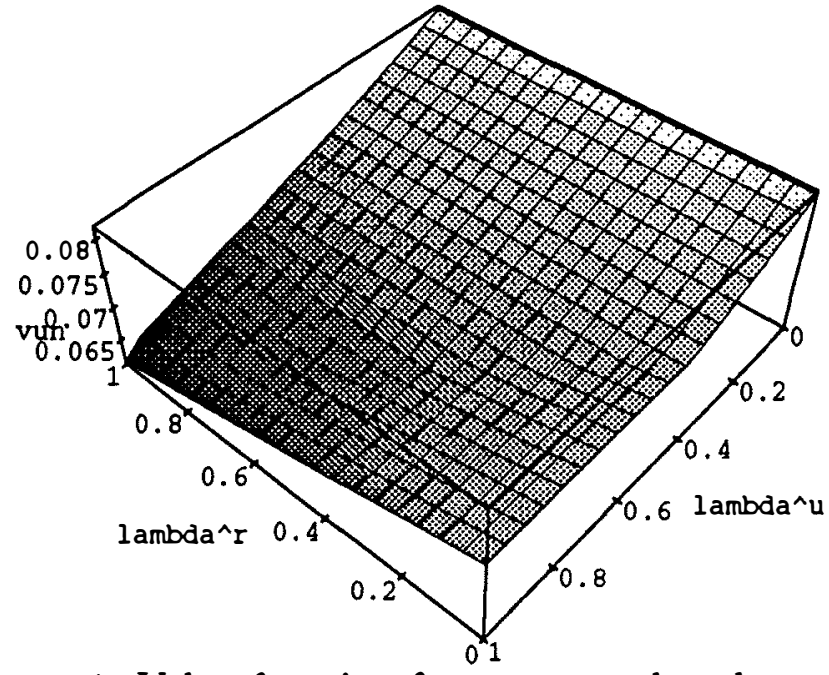

Figure 4: Value function for an unemployed agent in sector $u$ 
This in turn allows us to compute the probabilities of agents migrating as a function of their beliefs. Figures 5 and 6 show the probabilities $q_{r u}^{\lambda^{r}, \lambda^{u}}$ and $q_{u r}^{\lambda^{r}, \lambda^{u}}$ respectively (the probability of an agent in $r$ with any given beliefs migrating to $u$, and the probability of an agent in $u$ with any given beliefs migrating to $r$, resp.).

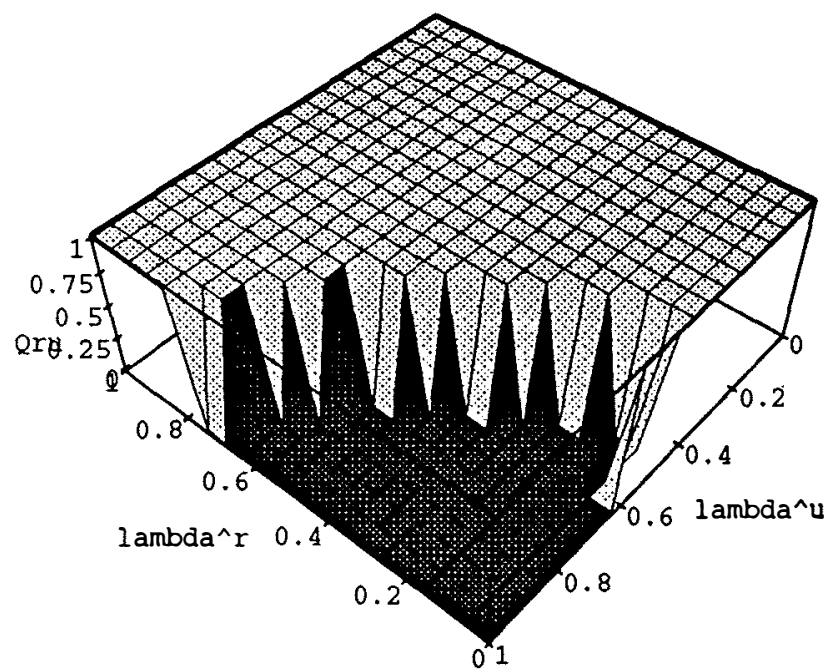

Figure 5: Probability of an agent in sector $r$ migrating to $u$

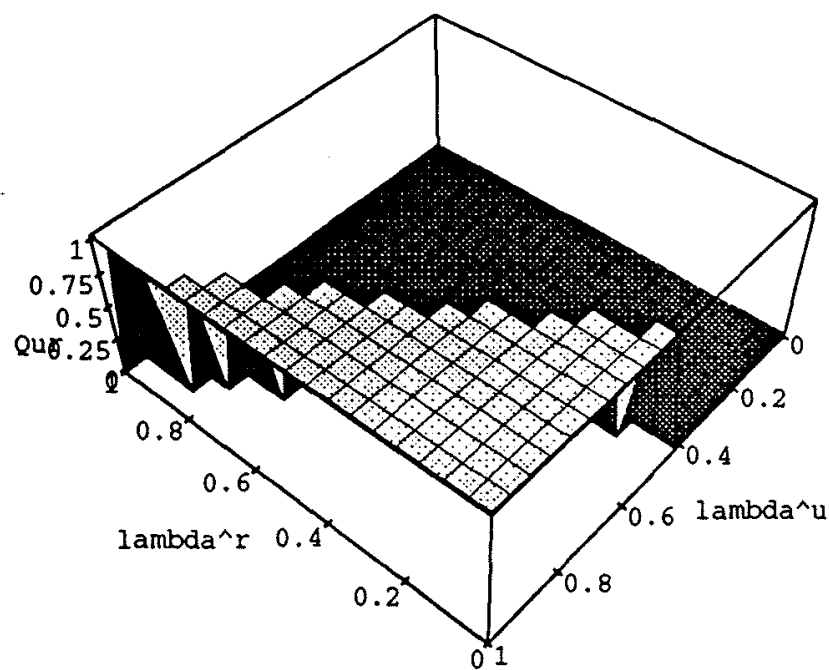

Figure 6: Probability of an agent in sector $u$ migrating to $r$ 


\subsection{Aggregate dynamics, and government's beliefs}

Now we can move on to the aggregate dynamics, and solving the government's welfare maximization problem. Let the government be completely uninformed about the beliefs of the agents during this period, and hence assign the beliefs: $\mu_{t}^{r r}=\mu_{t}^{r u}=\mu_{t}^{u r}=\mu_{t}^{u u}=$ $U([0,1])$. Then we can compute the probability of $N_{t+1}^{r}$ moving to any given value given that $N_{t}^{r}=30$ (notice that in this example, the government actually knows the exact empirical wage distribution in $t$ by simply knowing $N_{t}^{r}$ ). The probabilities $T_{30, m}^{\mu_{t}}$ are displayed in Figure 7. The chosen values are again in the spirit of the Harris-Todaro world with 20 unemployed in the urban sector, and the expected wage differential being large enough to induce even further migration to the urban sector.

We can now proceed to study the aggregate dynamics from the government's point of view. For instance, if period $t$ witnesses 10 agents migrating from $r$ to $u$, and 2 agents migrating from $u$ to $r$, then, we can go through the four steps of updating the government's prior from $\mu_{t}$ which is uniform over $[0,1]$, to the beliefs shown in the four histograms in Figures 8-11. 


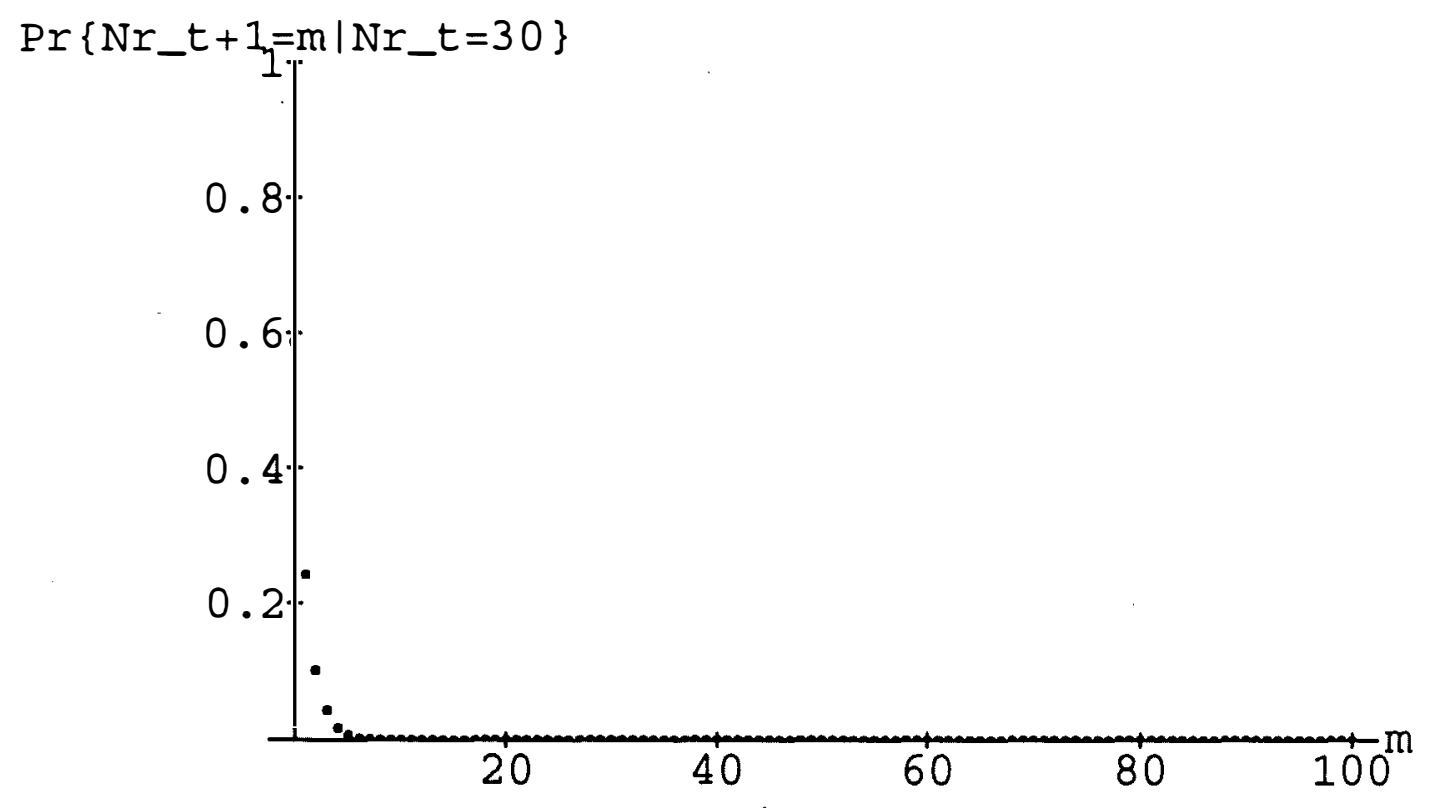

Figure 7: The probability of $N_{t+1}^{r}=m$ given $N_{t}^{r}=30$ 


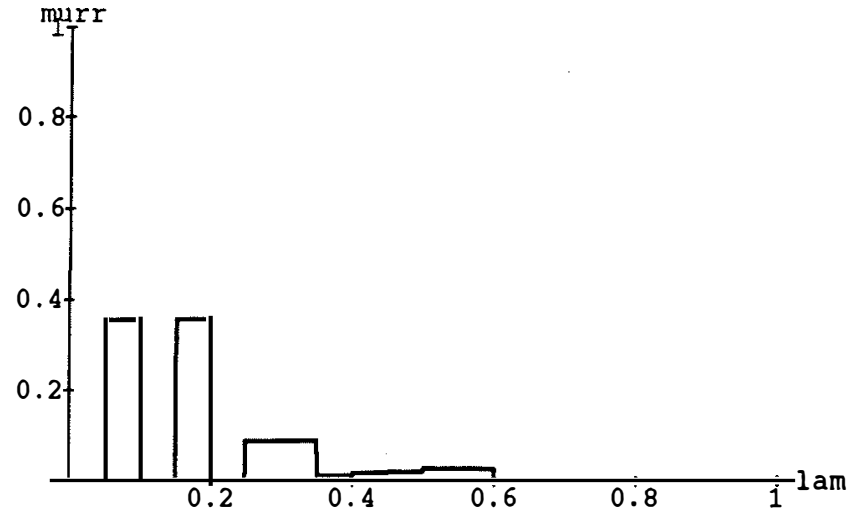

Figure 8: The government's belief $\mu_{t+1}^{r r}\left(\lambda^{r}\right)$ if $10 r \rightarrow u$ and $2 u \rightarrow r$

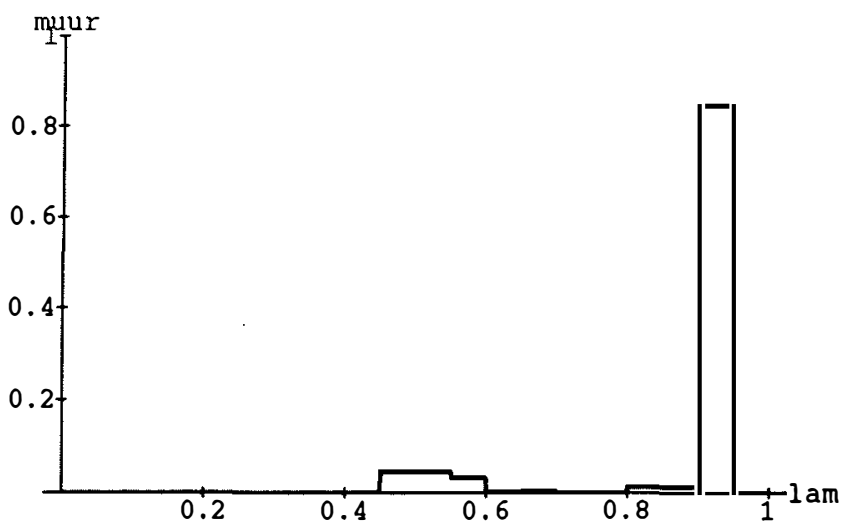

Figure 10: The government's belief $\mu_{t+1}^{u r}\left(\lambda^{r}\right)$ if $10 r \rightarrow u$ and $2 u \rightarrow r$

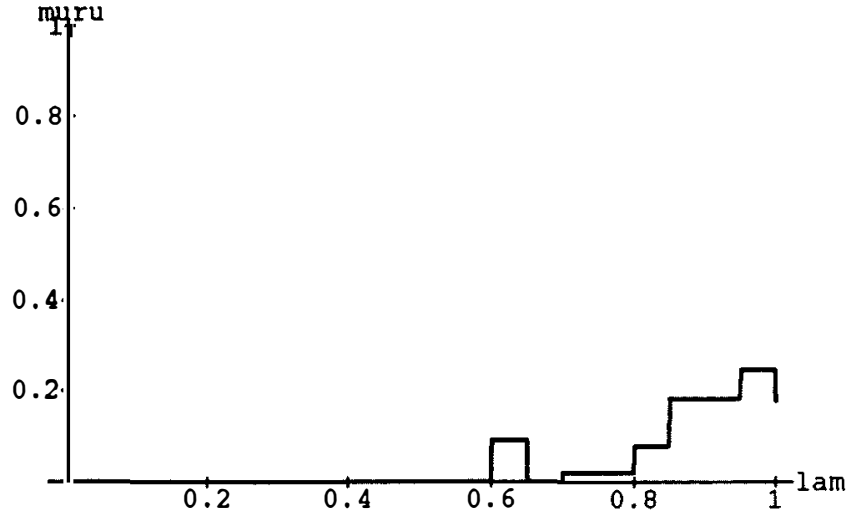

Figure 9: The government's belief $\mu_{t+1}^{r u}\left(\lambda^{u}\right)$ if $10 r \rightarrow u$ and $2 u \rightarrow r$

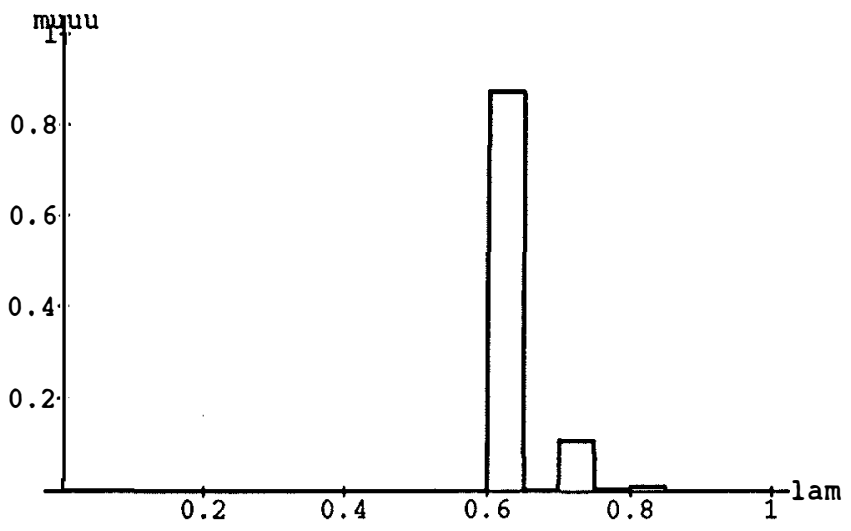

Figure 11: The government's belief $\mu_{t+1}^{u u}\left(\lambda^{u}\right)$ if $10 r \rightarrow u$ and $2 u \rightarrow r$ 


\subsection{The Government's Optimal Policy Function}

Let the government's utility function $U\left(c_{1}, \ldots, c_{N}\right)=\sum_{i=1}^{N} u\left(c_{i}\right)=\sum_{i=1}^{N} \sqrt{c_{i}}$, and let $Q($ surplus $)=$ surplus. We can now - in principle - solve our government's value function (of section 5) by iterating on the functional equation in the same manner we used to solve the individual's dynamic program. In the general case, this is a rather complicated procedure where the government's own belief $\mu_{t}$ is a state variable since it makes the value function very highly dimensional if we maintain any reasonable degree of accuracy. To illustrate the solution, we solve for the government's optimal policy as a function of $N_{t}^{r}$, the current population distribution, in a special case where the government's value function does not depend on $\mu_{t}$ (by assuming that the government does not update its beliefs $\mu_{t}$ ). The solution discussed below was implemented by solving for the agents' optimal migration rules for all possible values of $N_{t}^{r}$ in the same manner discussed earlier in this section. We then iterate on the government's value function (with $\mu_{t}$ fixed at the uniform distribution) until the difference between two iterates was less than $5 \times 10^{-6}$, this took 15 iterations and approximately 4400 CPU seconds on the Cray YMP2E/116.

We consider the case where $\delta=\beta=0.25$, and the government does not update its beliefs, i.e. $\mu_{t}^{i j}=U[0,1]$. The government still cares about migration patterns, however, since they affect the lifetime payoffs of the subjects. Figures 12-15 show the government's value function, and the optimal $s_{t}^{r} \in\{0.0,0.05,0.1,0.15,0.2,0.25\}$, $s_{t}^{u} \in\{0.0,0.05,0.1,0.15,0.2,0.25\}$ and $\tau_{t+1} \in\{0.0,0.1,0.2,0.3,0.4,0.5\}$ respectively as a function of $N_{t}^{\tau}$, for that special case. We can see from Figure 12 that the government is able to maintain a flat value function for most population distributions by distributing wage subsidies and financing them through migration taxes. The subsidies $s_{t}^{r}$ and $s_{t}^{u}$ are monotone increasing in the populations $N_{t}^{r}$ and $N_{t}^{u}$ respectively, and the migration tax is fixed at 0.1 for all but the very extreme population distributions. 


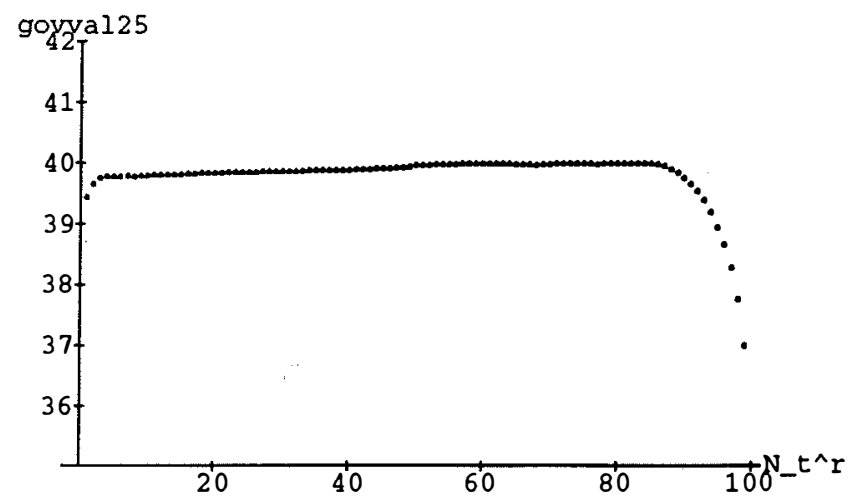

Figure 12: Value function of the government for $\delta=0.25$, no updating

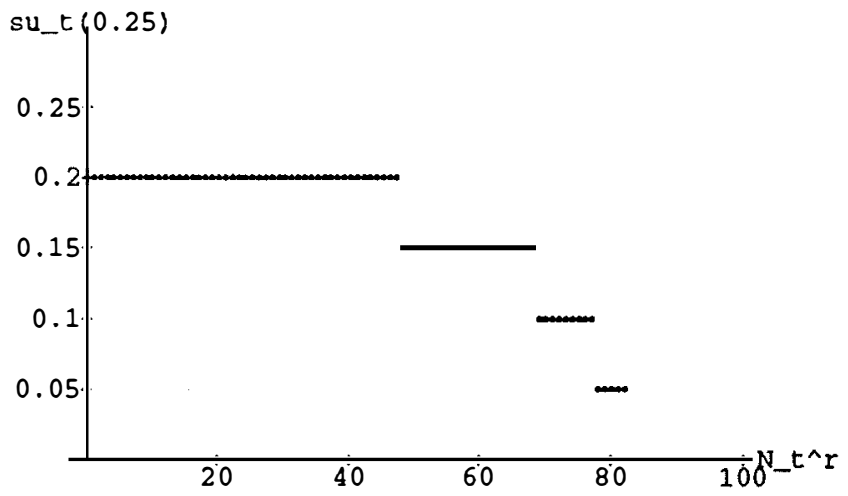

Figure 14: Optimal subsidy $s_{t}^{u}$ for $\delta=.0 .25$, no updating

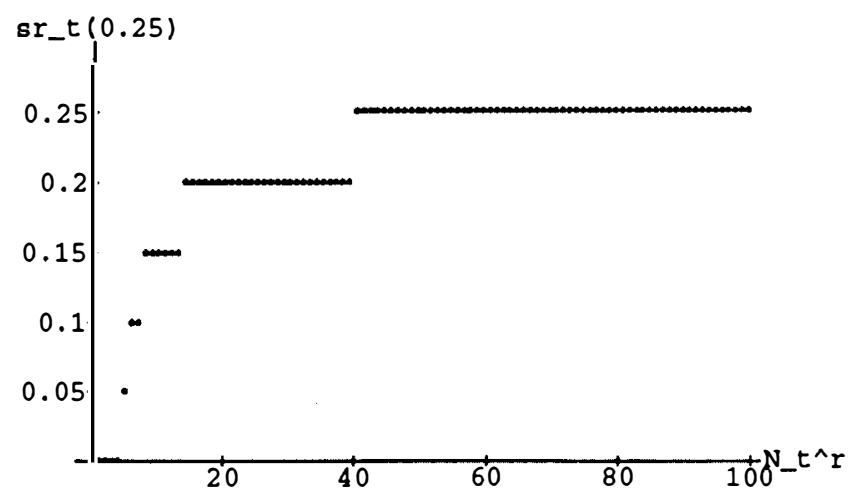

Figure 13: Optimal subsidy $s_{t}^{r}$ for $\delta=0.25$, no updating

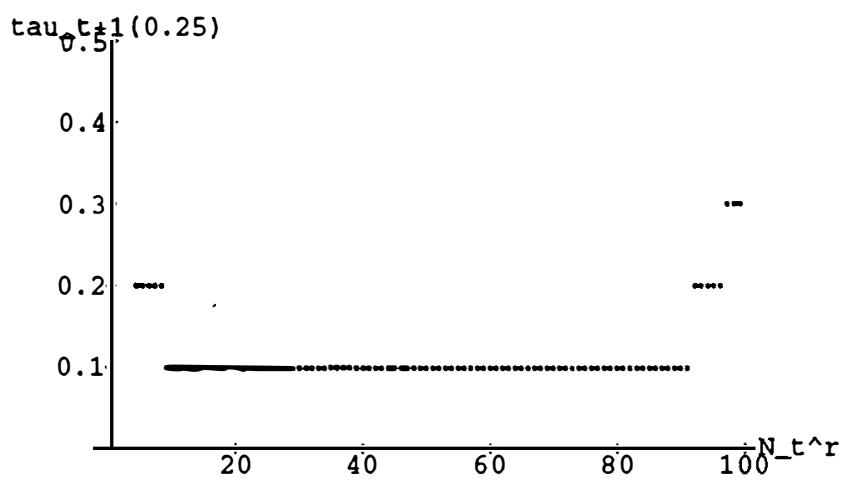

Figure 15: Optimal migration tax $\tau_{t+1}$ for $\delta=0.25$, no updating 


\section{References}

Bhagwati, J. N. and T. N. Srinivasan, 1974, On Reanalyzing the Harris-Todaro Model: Policy Rankings in the Case of Sector-Specific Sticky Wages, American Economic Review 64(3), 502-508.

Calvo, G. A., 1978, Urban Unemployment and Wage Determination in LDCs: Trade Unions in the Harris-Todaro Model, International Economic Review 19, 65-81.

Corden, W. M. and R. Findlay, 1975, Urban Unemployment, Intersectoral Capital Mobility and Development Policy, Economica 62, 59-78.

Djiajić, S., 1989, Migrants in a Guest-Worker System: A Utility Maximizing Approach, Journal of Development Economics 31, 327-339.

Easley, D. and N. Kiefer, 1988, Controlling a Stochastic Process with Unknown Parameters, Econometrica 56, 1045-1064.

El-Gamal, M., 1992, The Rational Expectations- $n(\epsilon) \epsilon$-Equilibrium, Social Science Working Paper \# 823, Caltech.

El-Gamal, M. and R. Sundaram, 1993, Bayesian Economists ... Bayesian Agents: An Alternative Approach to Optimal Learning, Journal of Economic Dynamics and Control $17,355-383$.

Galor, Oded, 1986, "Time Preference and International Labor Migration", Journal of Economic Theory 38.

Harris, J. and M. Todaro, 1970, Migration, Unemployment and Development: A Two Sector Analysis, American Economic Review 60, 126-142.

Khan, M. A., 1980, The Harris-Todaro Hypothesis and the Hecksher-Ohlin-Samuelson Trade Model, Journal of International Economics 10, 527-547.

Lundborg, P., 1990, Rural Urban Migration and the Transition from Traditional to Modern Agriculture, Journal of Development Economics 33, 287-307.

Maitra, 1968, Dynamic Programming on Compact Metric Spaces, Sankhya (Series A) 30, 211-221.

McCool, T., 1982, Wage.Subsidies. and Distortionary Taxes in a Mobile Capital HarrisTodaro Model, Economica 49, 69-79.

Pessino, C., 1991, Sequential Migration Theory and Evidence From Peru, Journal of Development Economics 26, 55-87.

Pollachek, S. and F. Horvath, 1977, A Life Cycle Approach to Migration: Analysis of the Prespicacious Pregrinator, in: R. Ehrenberg (ed.), Research in Labor Economics Vol I., 
JAI Press, Greenwich, CT.

Stiglitz, J. E., 1974, Alternative Theories of Wage Determination and Unemployment in LDCs: The Labor-Turnover Model, Quarterly Journal of Economics 88, 194-227. 